\title{
Towards the use of (pseudo) nucleobase substituted amphiphiles as DNA nucleotide mimics and antimicrobial agents $\uparrow$
}

\author{
Kendrick K. L. Ng, ${ }^{a}$ Milan Dimitrovski, ${ }^{a}$ Jessica E. Boles, ${ }^{a / b}$ Rebecca J. \\ Ellaby, ${ }^{a}$ Lisa J. White ${ }^{a}$ and Jennifer R. Hiscock*a \\ ${ }^{a}$ Dr J. R. Hiscock, School of Physical Sciences, University of Kent, Canterbury, UK, \\ CT2 7NH; E-mail: J.R.Hiscock@Kent.ac.uk; Tel: +44(0)1227816467. \\ ${ }^{b}$ School of Biosciences, University of Kent, Canterbury, UK, CT2 7NH.
}

This work was supported by Public Health England, through the funding of a PhD studentship (J. E. Boles) and further supported by the University of Kent. The authors would like to thank K. Howland for his assistance with mass spectrometry during the project.

$\uparrow$ Electronic Supplementary information (ESI): This includes experimental details, NMR, mass spectrometry, dynamic light scattering, zeta potential, surface tension and critical micelle concentration, solution state association constant determination, low level computational modelling, biological and crystallography data. See DOI: 


\section{Towards the use of (pseudo) nucleobase substituted amphiphiles as DNA nucleotide mimics and antimicrobial agents $\uparrow$}

Here we present the synthesis of complementary (pseudo) nucleobase appended Supramolecular Self-associating Amphiphilic (SSA) salts and, establish the potential for this molecular construct to produce a new class of DNA inspired synthetic structures/materials. The anionic component of this class of amphiphile contains multiple hydrogen bond donating and accepting functionalities, meaning that these systems can access multiple self-associative hydrogen bonding modes simultaneously. Herein, we characterise the self-associative properties of these DNA inspired amphiphiles in the solid state, solution state and gas phase. Finally, we investigate the potential of these amphiphilic salts to act as antimicrobial agents against model Gram-positive (methicillin resistant Staphylococcus aureus - MRSA) and Gram-negative (Escherichia coli - E. coli) bacteria.

Keywords: self-association; hydrogen bonding; host-guest chemistry; amphiphile; antimicrobial.

$\dagger$ Electronic Supplementary information (ESI): This includes experimental details, NMR, mass spectrometry, dynamic light scattering, zeta potential, surface tension and critical micelle concentration, solution state association constant determination, low level computational modelling, biological and crystallography data. See DOI:

\section{Introduction}

Hydrogen bond formation, electrostatic interactions, charge transfer and solvent-solute interactions can all play a role in supramolecular self-association and the stabilisation of any resultant aggregate formation.[1-3] The aggregates that are formed as a result of molecular self-association events have been utilised in multiple areas from programmable nanostructures[2,4-6] and supramolecular organic frameworks,[7] to soft material (gel) design.[8,9] Of these non-covalent or supramolecular interactions, hydrogen bonds have been shown to be effective in the formation of novel nanostructures/materials. Current examples of this approach to self-associated system design incudes work by Lv and co-workers[10] who have shown the potential of 
conjugated polymer nanogels to act as sustainable drug delivery materials; Sun and coworkers[11] who have shown hydrogen bonded organic frameworks to act as anticancer drug delivery vehicles; and Steed and co-workers[12] who have used hydrogen bonds as a replacement to covalent bonds in the design of soft materials. This body of work alone highlights the importance of hydrogen bond formation in molecular self-association and material formation events, and thus the need to understand and control these interactions at the molecular level.

Although the formation of hydrogen bond donor (HBD):anion complexes have been well studied, $[13,14]$ there are comparatively few examples of HBD arrays that are covalently incorporated into the structure of low molecular weight anions (typically < $500 \mathrm{amu}$ ). Gale and co-workers have provided one of the few examples in this area, whereby the anionic component of the salts produced are able to selectively coordinate to neutral phosphates over anionic competing species.[15] Here the proximity of the anionic component to the HBD receptor cavity introduces an element of columbic repulsion, in turn decreasing the affinity of an anionic guest towards the receptors cavity.

Faustino and co-workers were among the first to incorporate this class of motif (in this instance an anion-spacer-urea group) into the structure of amphiphilic monomers.[16] Initial results produced for this class of compounds showed these amphiphiles to exhibit similar critical micelle concentrations (CMC) to sodium decanoate;[17] a property that was attributed to the formation of intermolecular, selfassociative hydrogen bonding interactions between the anionic units of these amphiphilic salts. Our own efforts have expanded this area of self-associative system, through the development of a library of > 30 Supramolecular Self-associating 
Amphiphilic (SSA) salts published to date, the general structure of which is shown in Figure 1a.[18-23]

SSAs are 'frustrated' in nature, meaning that the anionic component of these amphiphilic salts can adopt multiple self-associative hydrogen bonding modes simultaneously, as this unit contains multiple HBD or hydrogen bond acceptor units (HBA). The exact number of HBA and HBD groups varies depending on $\mathrm{R}$ group substituents however, all SSAs contain at least one HBD-HBA thio/urea functionality and one HBA anion. Single crystal X-ray diffraction studies have confirmed that a single SSA anion may adopt a number of different self-associative bonding modes including the formation of thio/urea-anion dimers, thio/urea-anion tapes and thio/ureathio/urea stacks (Figure 1b).[18] The preference for one hydrogen-bonding mode over another was found to be dependent on the counter cation present. The more strongly coordinating SSA counter cations instigate the formation of thio/urea-thio/urea hydrogen bonded stacks, whereas the presence of the comparatively weakly coordinating cations result in the formation of thio/urea-anion dimers. Moving from the solid state into the solution state,[20] we have been able to show that within a DMSO environment, the anionic component of SSAs self-associate to predominantly form hydrogen bonded thio/urea-anion dimers. However, in an aqueous solution we observe the formation of larger, spherical aggregates approximately $150-250 \mathrm{~nm}$ in hydrodynamic diameter. Within the scope of these studies, $[22,23]$ we have also been able to show a link between the strength of hydrogen bonded dimer formation in a DMSO solution and the CMC values obtained for that same SSA in an aqueous solution.

DNA is no longer considered a biomolecule which is only useful for recording genetic information. Instead, this biomolecule has now been utilized for the production 
of next generation materials with roles in electronics, diagnostics, medicine, materials science and synthetic biology.[24] These advancements have inspired the supramolecular chemistry community,[25] resulting in: (i) the use of DNA micelles as nanoreactors;[26] (ii) the synthesis of dynamic DNA nanotubes;[27] and (iii) the construction of synthetic polymers.[28] In addition, we have previously shown that the controlled balance of these hydrogen bonded complexation events within our SSA systems could lead to the ever more complex controlled assembly of DNA incorporated nanostructures.[19] Herein, we move our initial studies from an organic to an aqueous environment, exploring the self-associative properties of $\mathbf{2 , 3}, \mathbf{4}$ and $\mathbf{2}+\mathbf{4}$ in combination in the solid state, gas phase and solution state (both organic and aqueous). The results of these studies provide valuable information towards the development of pseudo synthetic DNA structures, such as those illustrated in Figure 2. In addition, to better understand the complex self-associative $(2,3$ and 4$)$ and SSA complexation interactions $(2+4$ in a 1:1 mixture), 5-7 have been synthesised to allow the investigation of those interactions that involve the (pseudo) nucleobases of SSAs 2-4 only. Finally, as other members from the SSA library have shown antimicrobial activity against clinically relevant Grampositive Methicillin resistant Staphylococcus aureus (MRSA),[21] we have undertaken antimicrobial screening studies against both model species MRSA and Gram-negative Escherichia coli (E. coli) to determine if 2-4 also exhibit antimicrobial properties.

\section{Synthesis}

Compounds 1,[22] 2[19] and 7[29] have been previously reported however, we present here an improved synthesis of $\mathbf{2}$, from previously published $\mathbf{1}$. Compound $\mathbf{2}$ was isolated as a white solid in a yield of $54 \%$, through the reaction of $N, N^{\prime}-$ dicyclohexylcarbodiimide (DCC) with thymine-1-acetic acid, 1 and $\mathrm{N}$ hydroxysuccinimide (NHS) in DMF. Compound 3 was prepared through the reaction of 
1-ethyl-3-(3-dimethylaminopropyl)carbodiimide (EDC) with 2-nitroisonicotinic acid and $\mathbf{1}$ in DMF and obtained as a bright yellow solid in a yield of $51 \%$. Compound 5 was synthesised through the reaction of 2-nitroisonicotinic acid and 4-(trifluoromethyl) aniline with carbonyldiimidazole (CDI) as the amide coupling agent in chloroform. The pure product was obtained as a yellow solid in a yield of $54 \%$. Compound $\mathbf{4}$ and $\mathbf{6}$ were obtained through the reduction of $\mathbf{3}$ and $\mathbf{5}$ respectively, using hydrazine hydrate and $\mathrm{Pd} / \mathrm{C} 10 \%$ in ethanol and obtained as white solids in yields of $84 \%$ and $75 \%$ respectively.

\section{Results and Discussion}

\subsection{Solid state self-association events}

Previously published single crystal X-ray data obtained for $\mathbf{2}$ showed the anionic component of this amphiphilic salt to self-associate through the formation of intermolecular hydrogen bonds between the anionic sulfonate and urea component of the molecule to produce a hydrogen bonded dimer.[19] This anion-urea dimer formation thus allowed further intermolecular hydrogen bond interactions to form using the amide and thymine nucleobase units covalently bound at the opposite end of the anionic structure, giving rise to an interlocked three-dimensional chain-mail type network.

The structure of $\mathbf{4}$ was designed to incorporate the same basic structure as $\mathbf{2}$, however, exchanging the thymine nucleobase for a complimentary adenine analogue, which shares the same principle hydrogen bond donating and accepting sites as the nucleobase itself. Figure 3 (see also ESI† Figure S26 and Table S2) shows the single crystal X-ray structure obtained for $\mathbf{4}$ from slow evaporation of a methanol/water mixture. Here the structure obtained demonstrates an intermolecular hydrogen bonded network that is far more complex than that previously identified for the complimentary 
SSA 2 however; we still observe the formation of the sulfonate-urea dimer. In addition, we also observe complimentary pseudo adenine (amino pyridine)- pseudo adenine (amino pyridine), amide-sulfonate and amino-sulfonate interactions.

The analogous single crystal X-ray structure obtained for $\mathbf{3}$ clearly demonstrates that the complexity of the hydrogen bonding networks observed for $\mathbf{4}$ is exacerbated because of the presence of the primary amino functionality. As Figure 4 (see also ESI $\dagger$ Figure S25 and Table S1) demonstrates, the substitution of the primary amino functionality for the nitro group limits the intermolecular hydrogen bonded networks that form between the anionic units of $\mathbf{3}$ to sulfonate-urea and amide-sulfonate complexation only. The remaining hydrogen bond accepting unit of the nitro pyridine ring is simply employed in the coordination of bridging molecules.

Further simplifying the molecular structure of $\mathbf{3}$, through removal of the tetrabutylammonium (TBA) urea-sulfonate functionalities gives rise to $\mathbf{5}$. Here the principle HBD and HBA groups are limited to the amide functionality and the nitro pyridine ring system. This results in a neutral molecule where molecular selfassociation occurs through the formation of amide-amide interactions only, as shown in Figure 5 (see also ESI† Figure S27 and Table S3).

\subsection{Gas phase self-association}

Previous gas phase electrospray ionisation mass spectrometry studies have shown the anionic component SSAs to be stabilized as a dimer under these experimental conditions.[22,23] The same was found to be true for those DNA inspired SSAs 2-4 however, for the first time the anionic trimer was also observed with 4 (Table 1, ESI† Figures S28-33 and Table S4). The stabilisation of hydrogen bonded dimers was also, more surprisingly, observed for 5 and $\mathbf{6}$ (ESI† Figures S34-37 and Table S5), indicating that the presence of these pseudo nucleobase units can stabilise self-associative 
interactions as demonstrated within the solid state. It is hypothesized that these interactions may be responsible for the hydrogen bonded trimer observed for the anionic component of 4 .

\subsection{Solution state self-association}

As we have shown previously the results of SSA self-association events alter depending on the solvent environment.[22,23] Within a DMSO- $d_{6}$ solution, SSAs usually form lower order species such as anionic, hydrogen bonded dimers, while in aqueous solutions, higher order aggregates are observed. It is possible to observe these lower order species through conventional solution state NMR techniques whereas, those larger, higher order structures adopt solid-like properties and tumble comparatively slowly within solution meaning that these structures become NMR silent, thus appearing to disappear from conventional solution state NMR spectra. It is the NMR silence of those larger self-associated structures that can be used within a quantitative, internally standardised NMR experiment to confirm the presence of these larger structures within the solution state in the first instance (ESI $\uparrow$ Figures S38-45).

The propensity for 2-4 and the 1:1 mixture of complementary SSAs $\mathbf{2}$ and $\mathbf{4}$ to form these NMR silent, higher order self-associated structures was derived in both DMSO- $d_{6}$ (standardized with $1.0 \% \mathrm{DCM}$ ) and $\mathrm{D}_{2} \mathrm{O}$ (standardized with $5.0 \% \mathrm{EtOH}$ ) solutions at a total SSA concentration of $111.12 \mathrm{mM}$ and $6.00 \mathrm{mM}$ respectively. The results of these experiments are summarised in Table 2.

The majority of SSAs tested to date have exhibited no evidence of higher order self-associated structures at $111.12 \mathrm{mM}$ in DMSO- $d_{6}$. However, unlike most SSAs 2 does instigate the formation of larger self-associated structures, which subsequently become NMR silent under these comparative solvent conditions (Table 2). Most surprising, is the lack of evidence supporting the presence of larger self-associated 
structures of 2 in a 19:1 $\mathrm{D}_{2} \mathrm{O}: \mathrm{EtOH}$ solution, as are commonly observed under these same experimental conditions for other SSAs, including 3 and 4. Interestingly, combining complimentary SSAs 2 and $\mathbf{4}$ in a 1:1 ratio at a total SSA concentration of $6.00 \mathrm{mM}$ substantially increases the total proportion of SSA incorporated into these higher order structures to approximately double that of SSA 4 only in the absence of 2. It is therefore plausible to hypothesise that complimentary interactions between these two SSAs, one baring the thymine nucleobase, the second exhibiting the pseudo adenine nucleobase, is responsible for increasing the proportion of SSA incorporated into these larger aggregate structures at a concentration of $6.00 \mathrm{mM}$.

For 3 and 4, where no evidence of extended aggregate self-association was observed at $6.00 \mathrm{mM}$ in a DMSO- $d_{6} / 1.0 \%$ DCM mixture, the size of those selfassociated structures present in solution was determined using ${ }^{1} \mathrm{H}$ NMR DOSY in the absence of the DCM standard at $298 \mathrm{~K}$ (ESI† Figures S46-47 and Tables S6-7). The results of these studies showed that the anionic and cationic components of these SSAs were not strongly coordinated within the solution state. A hydrodynamic diameter of $1.78 \mathrm{~nm}$ and $1.94 \mathrm{~nm}$ was determined for the anionic components of $\mathbf{3}$ and $\mathbf{4}$ respectively. However, this approximation of the hydrodynamic diameter, derived from the Stokes-Einstein equation, must be treated with caution as it assumes that the diffusing entity is a sphere and that the van der Waals volume of the molecular complex is large compared to that of the solvent.[30] This system also exists in fast exchange, which can cause further complications with data analysis.[31,32] Even with these experimental limitations, the size of those structures calculated for the anionic component of SSAs $\mathbf{3}$ and $\mathbf{4}$ are evidence to support the formation of lower order species such as dimers or possible trimers. To further investigate the self-associative events undertaken by $\mathbf{3}$ and $\mathbf{4}$ within this polar organic solvent environment, a series of 
${ }^{1} \mathrm{H}$ NMR dilution studies were undertaken in a DMSO- $d_{6} 0.5 \% \mathrm{H}_{2} \mathrm{O}$ solution, results of which are shown in Figures 6 and 7 for $\mathbf{3}$ and $\mathbf{4}$ respectively (ESI† Figures S48-53).

With increasing concentration of $\mathbf{3}$, a downfield change in chemical shift is observed for the NH resonances of the urea functionality, providing evidence for hydrogen bonded self-association using the urea HBD NHs. However, the upfield change in chemical shift observed for the amide $\mathrm{NH}$ with the increasing concentration of $\mathbf{3}$ is somewhat puzzling, as this is evidence for the breaking of any hydrogen bond involving the amide HBD functionality, with increasing concentration of SSA. We hypothesise that this change of chemical shift should instead be attributed either to inductive effects, or changes in local solvation environment created because of ureaanion hydrogen bond complex formation. These changes in chemical shift trends are also observed for the $\mathrm{NH}$ resonances of 4 . However, this SSA also contains a primary amino group, capable of acting as both a HBD or HBA. As the concentration of $\mathbf{4}$ is increased a small downfield change in chemical shift is observed. This change in chemical shift is too small to allow the calculation of any quantitative parameters, but does indicate that any hydrogen bonding interactions, which utilise this group, are weak. It is for this reason that when fitting those data shown in Figure 7 to a self-associative isotherm we have ignored the amino pyridine (pseudo adenine) unit in this instance. However, this does mean that any association constants generated from these data should be treated with caution.

To quantify the strength of the hydrogen bonded self-association events undertaken by 3 and 4 in a DMSO- $d_{6} 0.5 \% \mathrm{H}_{2} \mathrm{O}$ solution, the change in chemical shift values obtained for the urea $\mathrm{NH}$ resonances within the ${ }^{1} \mathrm{H}$ NMR dilution studies were fitted to both the dimerization/equal K (EK) model[33,34] (where the association constants for all self-associative effects are equal) and the cooperative equal $\mathrm{K}$ (CoEK) 
model (where the first association constant in the self-association process is different to the subsequent association constants which are all equal) using BindFit v0.5 (ESI $\uparrow$ Tables S9-10).[35,36] These models assume one component, one dimensional homogeneous aggregation only.[37]

From the ${ }^{1} \mathrm{H}$ NMR DOSY data obtained in DMSO- $d_{6}$, we know that the anionic portion of $\mathbf{3}$ and $\mathbf{4}$ self-associates to form lower order complexes, previous studies relating to other SSAs[19,21-23] also indicate the presence of hydrogen bonded dimeric species under these solvent conditions. In addition, the data gathered from the ${ }^{1} \mathrm{H} N M R$ dilution studies indicate that these self-association events rely on hydrogen bonded complex formation involving the urea NH's. Further to this, evidence obtained from the single crystal X-ray structure data for 3 and $\mathbf{4}$ (Figures 3 and 4) suggests these dimers are stabilised through the formation of intermolecular urea-sulfonate complexation. When fitting the urea NH dilution data to both the EK and CoEK models, lower errors were observed for the fit to the EK over the CoEK model. This observation also supports the formation of hydrogen bonded dimers, with dimerization constants of 0.71 $\mathrm{M}^{-1} \pm 0.7 \%$ and $0.89 \pm 0.3 \%$ calculated for 3 and 4 respectively.

Previous studies conducted with $\mathbf{2}$ under these same solvent conditions identified, that as with $\mathbf{3}$ and $\mathbf{4}$, the anionic component of this SSA also formed hydrogen bonded urea-anion dimers. This enabled secondary interactions to occur between neutral, complimentary organic molecules (such as amino pyridine) to the thymine nucleobases exposed on the free ends of the hydrogen bonded dimer.[19] Those data previously discussed, also suggest the same may be possible of complementary SSA 4. However, ${ }^{1} \mathrm{H}$ NMR titration experiments involving $\mathbf{2}$ and $\mathbf{4}$ simultaneously, under analogous experimental conditions (DMSO- $d_{6} 0.5 \% \mathrm{H}_{2} \mathrm{O}$ at 298 $\mathrm{K})$ proved too complex to allow the elucidation of any quantifiable association 
parameters. It was with this in mind that compounds 5-7 were synthesised in addition to the purchase of $\mathrm{TBA} \mathrm{HSO}_{4}$ to enable the simulation of single association events from the complex mixture observed through the interactions of $\mathbf{2}$ and 3 or $\mathbf{2}$ and 4 (ESI $\dagger$ Figures S60-67 and Tables S13-15).

The ${ }^{1} \mathrm{H}$ NMR titration of 7 into a solution of 3 in DMSO- $d_{6} 0.5 \% \mathrm{H}_{2} \mathrm{O}$ at $298 \mathrm{~K}$ showed no change in chemical shift for the urea or amide NH resonances, meaning that 3 will not readily interact with 7 under these experimental conditions. However, the analogous titration conducted with $\mathbf{4}$ and $\mathbf{7}$ did show slight deviations for the position of the primary amine HBD groups of $\mathbf{4}$ upon the addition of $\mathbf{7}$, confirming the formation of weak hydrogen bonded complexes between these (pseudo) nucleobases. These data show the potential for the formation of complimentary (pseudo) nucleobase intermolecular interactions between $\mathbf{2}$ and $\mathbf{4}$, which would not be expected for $\mathbf{2}$ and $\mathbf{3}$. The analogous ${ }^{1} \mathrm{H}$ NMR titration of $\mathrm{TBA} \mathrm{HSO}_{4}$ with both $\mathbf{3}$ and $\mathbf{4}$ did show notable changes in chemical shift for all NH resonances however, association constants calculated from these data should be treated with caution as there are competing selfassociation interactions which have not been accounted for when fitting data to 1:1, 1:2 or 2:1 host:guest isotherms. However, simplifying the structure of $\mathbf{3}$ to $\mathbf{5}$, removing the urea-sulfonate functionality does allow the elucidation of 1:1 host:guest association constants for 5:7 and 5: $\mathrm{TBA} \mathrm{HSO}_{4}$ in a DMSO- $d_{6} 0.5 \% \mathrm{H}_{2} \mathrm{O}$ solution at $298 \mathrm{~K}$. Under these experimental conditions, the association constants calculated were found to be $<$ $10 \mathrm{M}^{-1}$ for both complexation events. Interestingly the analogous titration experiments conducted with 6 (the simplified version of 4 (Figures 8 and 9), showed an initial upfield change in chemical shift (guest $=7$ or $\mathrm{TBA} \mathrm{HSO}_{4}$ ), followed by a downfield change in chemical shift after the addition of 1.5 equivalents of guest ( $\mathrm{TBA} \mathrm{HSO}_{4}$ only). This initial upfield change in chemical shift for the amide $\mathrm{NH}$ and amino $\mathrm{NH}_{2}$ amino 
signifies that these $\mathrm{NH}$ resonances are undergoing events, which result in increased electron density surrounding the hydrogen atoms of these NH HBD groups. The most obvious explanation for this effect is the hydrogen bonded self-association of $\mathbf{6}$, which is disrupted upon the addition of guest species, that out compete the hydrogen bonded self-association events through host-guest complex formation. The results of these titration studies, although not quantitative, also indicate that $\mathbf{4}$ and $\mathbf{2}$ may be capable of not only forming sulfonate-urea hydrogen bonded structures but also form complimentary (pseudo) nucleobase interactions.

As a result of the ${ }^{1} \mathrm{H}$ NMR titration studies shown in Figures 8 and $9,{ }^{1} \mathrm{H}$ NMR dilution studies were also conducted with 6 in a DMSO- $d_{6} 0.5 \% \mathrm{H}_{2} \mathrm{O}$ solution (ESI† Figures S58-59 and Table S12). The results of these studies confirm the presence of hydrogen bonded self-association events. Fitting these data obtained for both the amide and amino $\mathrm{NH}$ groups to both the EK and CoEK model confirms the EK model to be the most appropriate fit. Dimerization constants were determined from the outputs of the EK model for the $\mathrm{NH}_{2}\left(258 \mathrm{M}^{-1} \pm 1.9 \%\right)$, amide $\mathrm{NH}\left(10 \mathrm{M}^{-1} \pm 4.9 \%\right)$ and $178 \mathrm{M}^{-1}$ $\left( \pm 5.8 \%\right.$ ), when considering the $\mathrm{NH}_{2}$ and amide $\mathrm{NH}$ groups simultaneously. The most appropriate fit for these data considers only the amino $\mathrm{NH}_{2}$ group, which seems plausible when considering the hydrogen bonded motifs observed within the crystal structure of 4 (Figure 3), where amino pyridine-amino pyridine interactions can be observed.

Moving from the study of those lower order self-association events, principally observed for 2-4 in DMSO, to those larger structures predominantly observed in 19:1 $\mathrm{H}_{2} \mathrm{O}:$ EtOH solutions, a variety of complimentary methods including dynamic light scattering (DLS) (ESI $\uparrow$ Figures S68-83 and Table S16), zeta potential (ESI $\uparrow$ Figures S84-87 and Table S17) and tensiometry techniques (ESI $\uparrow$ Figures S88-91 and Table 
S18) were used to characterise those larger SSA aggregates present within this solvent environment. The surfactant properties for solutions of $\mathbf{2 , 3 , 4}$ and $\mathbf{2 + 4}$ supplied in a 1:1 molecular ratio was determined using the pendant drop method at $298 \mathrm{~K}$. The CMC value was determined as the point at which the surface tension was no longer found to decrease with increasing concentrations of compound.[38] A full overview of these results is provided in Table 3. The CMC value derived for these systems was found to be higher than the concentrations at which the DLS and associated zeta potential measurements were performed (Table 4), however this does not mean that stable aggregates do not exist in solution.[39]

When considering the data summaries provided in Tables 3 and 4, interestingly the stability of those aggregates produced by $\mathbf{2}+\mathbf{4}$ (zeta potential $=-43 \mathrm{mV}$ ) when supplied in a 1:1 molar equivalence, is far greater than that of $\mathbf{2}$ only (zeta potential = $14 \mathrm{mV}$ ). However, the aggregates produced by $\mathbf{2 + 4}$ are shown to be less stable than those produced through the self-association of $\mathbf{3}$ only $(-54 \mathrm{mV})$. This suggests that the presence of the complementary SSA (4) can stabilise those self-associated aggregates produced by 2 only.

These observations are reiterated when comparing the CMC values of 4 (4.24 $\mathrm{mM})<\mathbf{2 + 4}(>10.00 \mathrm{mM})$ and $\mathbf{2}(24.98 \mathrm{mM})$ only. An exact value could not be obtained for the $2+4$ 1:1 mixture due to solubility limitations. The corresponding DLS studies conducted with $2,3,4$ and $2+4$ under analogous conditions showed that the selfassociated structures produced at a concentration of $3.0 \mathrm{mM}$ by this group of SSAs varied in hydrodynamic diameter from $\approx 100-230 \mathrm{~nm}$. Upon decreasing the concentration of these solutions by a factor of 10 to $0.3 \mathrm{mM}$, a marked difference was observed for either aggregate size or the polydispersity of the sample for all solutions tested, with the exception of that which contained a 1:1 mixture of $\mathbf{2}$ and $\mathbf{4}$. This again 
suggests that the mixture of complimentary (pseudo) nucleobase substituted SSAs results in the formation of stabilised aggregates.

\subsection{Antimicrobial SSA activity}

As detailed previously, members from this class of compounds have been shown to act as antimicrobial agents against clinically relevant MRSA USA300.[21] This original proof of concept study showed that incorporating not only the urea-sulfonate functionality, but also electron rich (anthracene) and electron poor (anthraquinone) hydrophobic aromatic substituents into the scaffold of two complimentary anionic SSA substituents, not only increased and stabilised the associative properties of these SSAs when supplied in combination (as a 1:1 mixture) but also increased the system's antimicrobial efficacy. With these results in mind we aimed to establish if $\mathbf{2 - 4}$ could also demonstrate antimicrobial activity and if the effects of co-formulating complimentary $\mathbf{2}$ and $\mathbf{4}$ as a 1:1 mixture would increase any antimicrobial activity.

Antimicrobial activity screening studies were conducted with 2, 3, 4 and 2+4 (supplied in a 1:1 molar ratio) against both model Gram-positive MRSA (Figure 10a) and Gram-negative E. coli (Figure 10b) bacteria, at a SSA concentration of $3.3 \mathrm{mM}$. The bacterial growth in this instance is monitored thourgh the use of optical density measurements (OD). Here, we define an SSA to be of interest as a potential antimicrobial agent if the presence of a compound can decrease the optical density (OD) measurement by $>10 \%$ after 900 mins under the experimental conditions described in Figure 10, Table 5 and the appropriate experimental methods within the ESI. $\uparrow$ The results of these screening studies are also overviewed in Table 5 for convenience. Interestingly, $\mathbf{3}$ is the only SSA from those tested here, to be of interest as a potential antimicrobial agent under these experimental conditions, against both our model Grampositive and Gram-negative bacteria. 
Interestingly, SSA 3 is the only amphiphile from those tested not to exhibit selfassociative interactions at both the anionic head group and (pseudo) nucleobase tale simultaneously. This leads us to hypothesize that although the construction of SSA pseudo DNA may be possible using this kind of approach to monomer design; it is unlikely to maintain the antimicrobial properties demonstrated by other members from this family of compounds, meaning some SSA structural development is required for both properties to be maintained simultaneously.

\section{Conclusions}

We have synthesised a complimentary adenine inspired SSA to complement our previously published thymine nucleobase substituted SSA. Building on these previous results, we have shown that this approach to 'frustrated' amphiphile design, incorporating combinations of different HBD (urea, thymine, primary amine and amide) and HBA (carbonyl oxygen, pyridine and sulfonate) groups show the potential for development as synthetic DNA analogues. Single crystal X-ray studies show $\mathbf{2 - 4}$ to selfassociate through the formation of urea-sulfonate dimerization. This leaves the (pseudo) nucleobase substituent free to undergo further self-associative interactions. The presence of SSA anion dimerization was confirmed in the gas phase, alongside the formation of SSA anion trimers (4 only) for the first time. Moving into the solution state, ${ }^{1} \mathrm{H}$ NMR studies confirmed the presence of predominantly lower order selfassociated species within a DMSO- $\mathrm{d}_{6}\left(0.5 \% \mathrm{H}_{2} \mathrm{O}\right)$ solution. While moving into a 1:19 EtOH: $\mathrm{D}_{2} \mathrm{O} / \mathrm{H}_{2} \mathrm{O}$ solution instigated the formation of extended aggregates (with the exception of 2 ), the hydrodynamic diameter of which was estimated to between $\approx 100$ $230 \mathrm{~nm}$, as opposed to the lower order species predominantly observed in a DMSO- $\mathrm{d}_{6}$ solution $(\approx 1.5 \mathrm{~nm})$. Additional ${ }^{1} \mathrm{H}$ NMR titration experiments conducted with $\mathbf{3}, \mathbf{4}$, and simplified compounds 5-7 and $\mathrm{TBA} \mathrm{HSO}_{4}$ were able to support the hypothesis, 
illustrated in Figure 2, that this type of SSA construct has the potential to from pseudo DNA structures. Initial assessment of the antimicrobial activity of 2-4 against model Gram-positive (MRSA) and Gram-negative (E. coli) bacteria showed only 3 to be of interest as a potential antimicrobial agent. However, this represents an interesting observation as $\mathbf{3}$ is the only SSA, of those tested, where the anionic component of this amphiphilic salt is not thought to undergo extensive hydrogen bond mediated selfassociation interactions which utilise the (pseudo) nucleobase/hydrophobic tail of the SSA anionic component.

\section{Acknowledgements}

This work was supported by Public Health England, through the funding of a PhD studentship (J. E. Boles) and the University of Kent. The authors would like to thank K. Howland for his assistance with mass spectrometry during the project.

\section{References}

1. Wang C, Wang Z, Zhang X. Amphiphilic Building Blocks for Self-Assembly: From Amphiphiles to Supra-amphiphiles. Acc. Chem. Res.. 2012 Apr;45(4):608-618.

2. Yu G, Jie K, Huang F. Supramolecular Amphiphiles Based on Host-Guest Molecular Recognition Motifs. Chem. Rev.. 2015 Aug 12;115(15):7240-7303.

3. Hunter CA. Quantifying intermolecular interactions: Guidelines for the molecular recognition toolbox. Angew. Chem. Int. Ed.. 2004;43(40):5310-5324.

4. Kumar S, Ludwig K, Schade B, et al. Introducing Chirality into Nonionic Dendritic Amphiphiles and Studying Their Supramolecular Assembly. Chem. Eur. J.. 2016 Apr 11;22(16):5629-5636.

5. Thota BNS, Urner LH, Haag R. Supramolecular Architectures of Dendritic Amphiphiles in Water. Chem. Rev.. 2016 Feb 24;116(4):2079-2102.

6. Wang J, Wang X, Yang F, et al. Effect of Topological Structures on the SelfAssembly Behavior of Supramolecular Amphiphiles. Langmuir. 2015 Dec 29;31(51):13834-13841. 
7. Tian J, Chen L, Zhang DW, et al. Supramolecular organic frameworks: engineering periodicity in water through host-guest chemistry. Chem. Commun.. 2016;52(38):6351-6362.

8. Sangeetha NM, Maitra U. Supramolecular gels: Functions and uses. Chem. Soc. Rev.. 2005 2005;34(10):821-836.

9. Steed JW. Supramolecular gel chemistry: developments over the last decade. Chem. Commun.. 2011 2011;47(5):1379-1383.

10. Senthilkumar T, Lv F, Zhao H, et al. Conjugated Polymer Nanogel Binding Anticancer Drug through Hydrogen Bonds for Sustainable Drug Delivery. ACS Appl. Bio Mater.. 2019;2(12):6012-6020.

11. He XT, Luo YH, Hong DL, et al. Atomically Thin Nanoribbons by Exfoliation of Hydrogen-Bonded Organic Frameworks for Drug Delivery. ACS Appl. Nano Mater.. 2019 Apr;2(4):2437-2445.

12. Hooper AE, Kennedy SR, Jones CD, et al. Gelation by supramolecular dimerization of mono(urea)s. Chem. Commun.. 2016;52(1):198-201.

13. Busschaert N, Caltagirone C, Van Rossom W, et al. Applications of Supramolecular Anion Recognition. Chem. Rev.. 2015 Aug;115(15):8038-8155.

14. Gale PA, Caltagirone C. Anion sensing by small molecules and molecular ensembles. Chem. Soc. Rev.. 2015;44(13):4212-4227.

15. Hiscock JR, Wells NJ, Ede JA, et al. Biasing hydrogen bond donating host systems towards chemical warfare agent recognition. Org. Biomol. Chem.. 2016 Oct;14(40):9560-9567.

16. Faustino CMC, Calado ART, Garcia-Rio L. New Urea-Based Surfactants Derived from alpha,omega-Amino Acids. J. Phys. Chem. B. 2009 Jan 29;113(4):977-982.

17. Faustino CMC, Calado ART, Garcia-Rio L. Dimeric and monomeric surfactants derived from sulfur-containing amino acids. J. Colloid and Interface Sci.. 2010 Nov 15;351(2):472-477.

18. Blackholly LR, Shepherd HJ, Hiscock JR. 'Frustrated' hydrogen bond mediated amphiphile self-assembly - a solid state study. CrystEngComm. 2016;18(37):7021-7028.

19. Gumbs TL, White LJ, Wells NJ, et al. 'Frustrated' hydrogen-bonded selfassociated systems as templates towards DNA incorporated nanostructure formation. Supramol. Chem.. 2018;30(4):286-295.

20. Hiscock JR, Bustone GP, Wilson B, et al. In situ modification of nanostructure configuration through the manipulation of hydrogen bonded amphiphile selfassociation. Soft Matter. 2016;12(18):4221-4228. 
21. Tyuleva SN, Allen N, White LJ, et al. A symbiotic supramolecular approach to the design of novel amphiphiles with antibacterial properties against MSRA. Chem. Commun.. 2019 Jan;55(1):95-98.

22. White LJ, Tyuleva SN, Wilson B, et al. Towards the Prediction of Global Solution State Properties for Hydrogen Bonded, Self-Associating Amphiphiles. Chem. Eur. J.. 2018 May;24(30):7761-7773.

23. White LJ, Wells NJ, Blackholly LR, et al. Towards quantifying the role of hydrogen bonding within amphiphile self-association and resultant aggregate formation. Chem. Sci.. 2017 Nov;8(11):7620-7630.

24. Stulz E, Clever G, Shionoya M, et al. DNA in a modern world. Chem. Soc. Rev.. 2011;40(12):5633-5635.

25. McLaughlin CK, Hamblin GD, Sleiman HF. Supramolecular DNA assembly. Chem. Soc. Rev.. 2011;40(12):5647-5656.

26. Trinh T, Chidchob P, Bazzi HS, et al. DNA micelles as nanoreactors: efficient DNA functionalization with hydrophobic organic molecules. Chem. Commun.. 2016;52(72):10914-10917.

27. Rahbani JF, Hariri AA, Cosa G, et al. Dynamic DNA Nanotubes: Reversible Switching between Single and Double-Stranded Forms, and Effect of Base Deletions. ACS Nano. 2015 Dec;9(12):11898-11908.

28. Surin M. From nucleobase to DNA templates for precision supramolecular assemblies and synthetic polymers. Polym.. 2016;7(25):4137-4150.

29. Vendrell-Criado V, Lhiaubet-Vallet V, Yamaji M, et al. Blocking cyclobutane pyrimidine dimer formation by steric hindrance. Org. Biomol. Chem.. 2016;14(17):4110-4115.

30. Macchioni A, Ciancaleoni G, Zuccaccia C, et al. Determining accurate molecular sizes in solution through NMR diffusion spectroscopy. Chem. Soc. Rev.. 2008;37(3):479-489.

31. Chen AD, Johnson CS, Lin M, et al. Chemical exchange in diffusion NMR experiments. J. Am. Chem. Soc.. 1998 Sep;120(35):9094-9095.

32. Aguilar JA, Adams RW, Nilsson M, et al. Suppressing exchange effects in diffusion-ordered NMR spectroscopy. J. Magn. Reson.. 2014 Jan;238:16-19.

33. Evstigneev MP, Buchelnikov AS, Kostjukov VV, et al. Indistinguishability of the models of molecular self-assembly. Supramol. Chem.. 2013 Apr;25(4):199203.

34. Stoesser PR, Gill SJ. Calorimetric Study of Self-Association of 6-Methylpurine in Water. J. Phys. Chem. 1967;71:564-567.

35. Thordarson P, Sewell K, Efremova V. Bindfit v0.5. http://supramolecular.org/. 
36. Martin RB. Comparisons of indefinite self-association models. Chem. Rev.. 1996 Dec;96(8):3043-3064.

37. von Krbek LKS, Schalley CA, Thordarson P. Assessing cooperativity in supramolecular systems. Chem. Soc. Rev.. 2017 May;46(9):2622-2637.

38. Pineiro A, Banquy X, Perez-Casas S, et al. On the characterization of host-guest complexes: Surface tension, calorimetry, and molecular dynamics of cyclodextrins with a non-ionic surfactant. J. Phys. Chem. B. 2007 May;111(17):4383-4392.

39. Ruckenstein E, Nagarajan R. Critical micelle concentration - transition point for micellar size distribution. J. Phys. Chem.. 1975;79(24):2622-2626. 
Table 1 - Summary of high-resolution electrospray ionisation mass spectrometry data obtained for the anionic component of 2-4.

\begin{tabular}{c|cc|cr|rc}
\multirow{2}{*}{ SSA } & \multicolumn{2}{|c|}{$\mathrm{m} / \mathrm{z}\left[\mathrm{M}^{-}\right.$} & \multicolumn{2}{|c|}{$\mathrm{m} / \mathrm{z}\left[\mathrm{M}+\mathrm{M}+\mathrm{H}^{+}\right]^{-}$} & \multicolumn{2}{c}{$\mathrm{m} / \mathrm{z}\left[\mathrm{M}+\mathrm{M}+\mathrm{M}+2 \mathrm{H}^{+}\right]^{-}$} \\
& Theoretical & Actual & Theoretical & Actual & Theoretical & Actual \\
\hline $\mathbf{2}^{a}$ & 410.0771 & 410.0755 & 821.1612 & 821.1591 & 1232.2453 & $b$ \\
\hline $\mathbf{3}$ & 394.0458 & 394.0440 & 789.0986 & 789.0951 & 1184.1514 & $b$ \\
\hline $\mathbf{4}$ & 364.0716 & 364.0702 & 729.1502 & 729.1471 & 1094.2288 & 1094.2227 \\
\hline
\end{tabular}

$a-$ Re-analysed, previously published data.[19] $b$-Complex not observed. 
Table 2: Percentage of SSA to become NMR silent, determined through comparative integration of ${ }^{1} \mathrm{H}$ NMR data obtained from: (i) a DMSO- $d_{6} / \mathrm{DCM}(1.0 \%)$ solution of SSA (total concentration $=111.12 \mathrm{mM})$; and (ii) $\mathrm{a} \mathrm{D}_{2} \mathrm{O} / \mathrm{EtOH}(5.0 \%)$ solution of SSA (total concentration $=6.00 \mathrm{mM}$ ). All quantitative ${ }^{1} \mathrm{H}$ NMR experiments were conducted with a delay time $\left(\mathrm{d}_{1}\right)$ of 60 seconds at $298 \mathrm{~K}$.

\begin{tabular}{c|c|c}
\multirow{2}{*}{ SSA } & \multicolumn{2}{|c}{ \% of SSA to become NMR silent } \\
& DMSO- $d_{6} \mathrm{w} / 1.0 \% \mathrm{DCM}$ & $\mathrm{D}_{2} \mathrm{O}$ w/ $5.0 \% \mathrm{EtOH}$ \\
\hline $\mathbf{2}^{*}$ & 6 & 0 \\
\hline $\mathbf{3}$ & 0 & 29 \\
\hline $\mathbf{4}$ & 0 & 32 \\
\hline $\mathbf{2}$ and $\mathbf{4}^{*}$ & 7 & 58
\end{tabular}

$*$ = average of three repeated experiments. 
Table 3. Overview of $\mathrm{CMC}$ and surface tension (obtained at $\mathrm{CMC}$ ) measurements obtained for 2-4 and 2+4 (supplied in a 1:1 molecular equivalence) in a 19:1 $\mathrm{H}_{2} \mathrm{O}: \mathrm{EtOH}$ solution at $298 \mathrm{~K}$.

\begin{tabular}{c|c|c} 
SSA & CMC $(\mathrm{mM})$ & Surface tension at CMC $(\mathrm{mN} / \mathrm{m})$ \\
\hline $\mathbf{2}$ & 24.98 & 53.70 \\
\hline $\mathbf{3}$ & 6.00 & 56.87 \\
\hline $\mathbf{4}$ & 4.24 & 57.70 \\
\hline $\mathbf{2 + 4}$ & $>10.00$ & Not determined
\end{tabular}


Table 4. Average intensity particle size distribution, rounded to the nearest whole number, for 2-4 and a 1:1 mixture of $\mathbf{2 + 4}$ calculated from 10 DLS runs at a total molecular concentration of $3.0 \mathrm{mM}$ and $0.3 \mathrm{mM}$. PDI = polydispersity index, rounded to the nearest whole number for the particle size distribution data. Average zeta potential values calculated, rounded to the nearest whole number, for 2-4 and a 1:1 mixture of $\mathbf{2 + 4}$, calculated from 10 runs at a total concentration of $3.0 \mathrm{mM}$. Samples were prepared in series, with an aliquot of the most concentrated solution undergoing dilution. Error $=$ standard error of the mean and is given to $1 \mathrm{dp}$.

\begin{tabular}{c|cc|cc|c}
\multirow{2}{*}{ SSA } & \multicolumn{2}{|c|}{ Peak maxima (nm) } & \multicolumn{2}{|c|}{ PDI (\%) } & Zeta potential \\
& $3.0 \mathrm{mM}$ & $0.3 \mathrm{mM}$ & $3.0 \mathrm{mM}$ & $0.3 \mathrm{mM}$ & $(\mathrm{mV})$ \\
\hline $\mathbf{2}$ & $147( \pm 7.4)$ & $126( \pm 2.9)$ & $25( \pm 0.7)$ & $22( \pm 0.3)$ & -14 \\
\hline $\mathbf{3}$ & $231( \pm 12.8)$ & $222( \pm 9.7)$ & $26( \pm 0.8)$ & $96( \pm 3.2)$ & -32 \\
\hline $\mathbf{4}$ & $189( \pm 3.0)$ & $128( \pm 2.7)$ & $24( \pm 0.4)$ & $14( \pm 2.5)$ & -54 \\
\hline $\mathbf{2 + 4}$ & $94( \pm 2.0)$ & $89( \pm 3.9)$ & $25( \pm 0.4)$ & $26( \pm 0.8)$ & -43
\end{tabular}


Table 5. Overview of average antimicrobial screening data $(n=3)$ obtained for $\mathbf{2 - 4}$ and a 1:1 combination of $\mathbf{2 + 4}$ at a total molar concentration of $3.3 \mathrm{mM}$, against model Grampositive MRSA and Gram-negative E. coli at an initial calibrated cell concentration equal to the 0.5 McFarland standard, after 900 mins. All SSAs were added in a 1:19 EtOH: $\mathrm{H}_{2} \mathrm{O}$ solution.

\begin{tabular}{c|c|c|c|c}
\multirow{2}{*}{ SSA } & \multicolumn{2}{|c|}{ MRSA } & \multicolumn{2}{c}{ E. coli } \\
\cline { 2 - 5 } & OD (abs.) & \% decrease in OD & OD (abs.) & \% decrease in OD \\
\hline \multirow{2}{*}{ control } & 1.12 & N/A & 0.70 & N/A \\
\hline $\mathbf{2}$ & 1.13 & 0 & 0.70 & 0 \\
\hline $\mathbf{4}$ & 0.64 & 43 & 0.58 & 0 \\
\hline $\mathbf{4}$ & 1.13 & 0 & 0.71 & 0 \\
\hline $\mathbf{2 + 4}$ & 1.09 & 3 & 0.71 & 0 \\
\end{tabular}




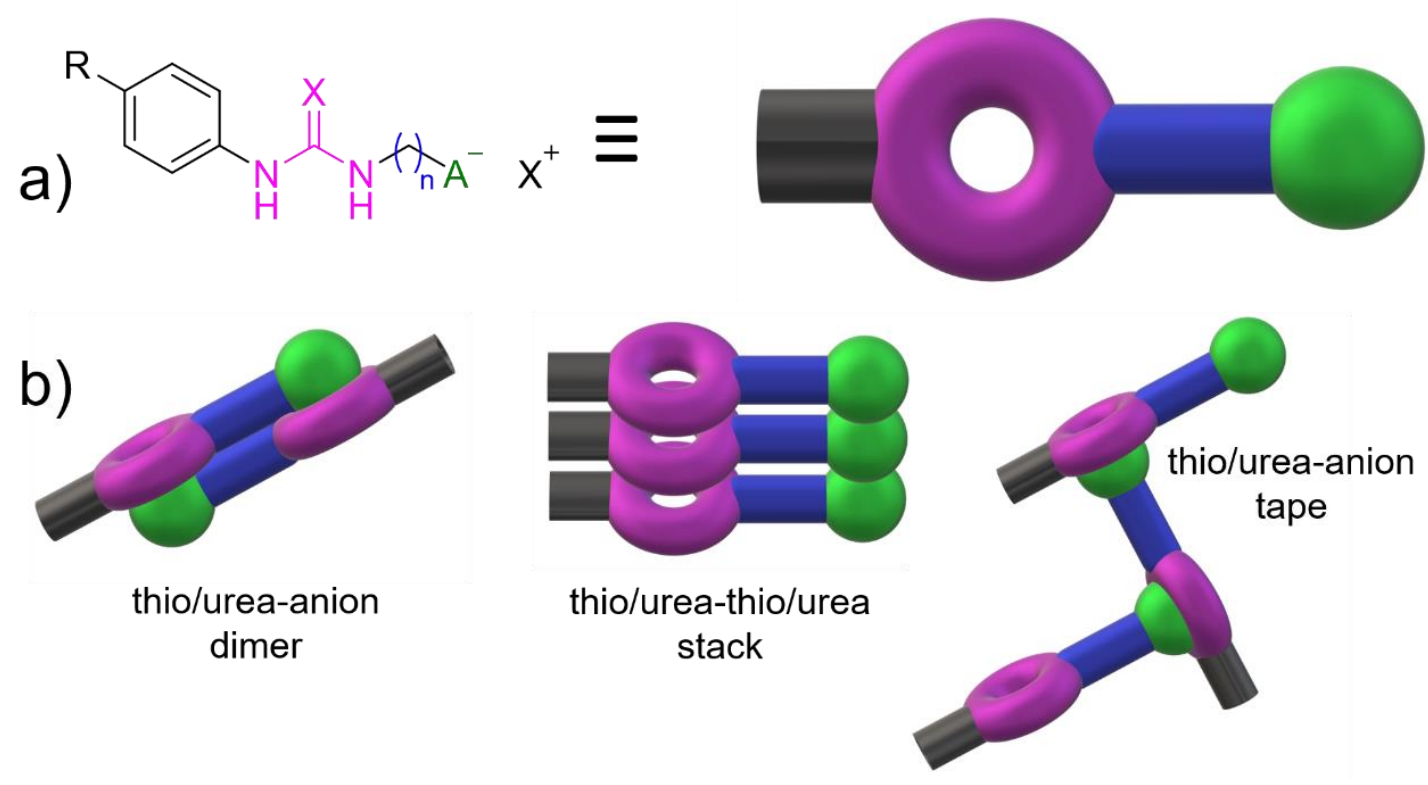

Figure 1. a) The general structure of an SSA: $\mathrm{R}=$ any group; $\mathrm{X}=\mathrm{S}$ or $\mathrm{O} ; \mathrm{n} \geq 1 ; \mathrm{A}^{-}=$ sulfonate or carboxylate; $\mathrm{X}^{+}=$counter cation; b) the different self-associative hydrogen bonding modes observed using single crystal X-ray diffraction techniques for the same anionic component of three SSAs. 


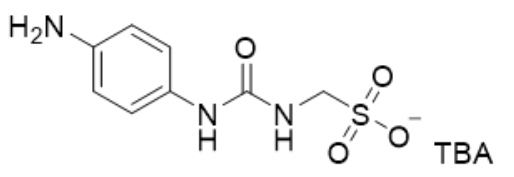

1<smiles>O=C(NCS(=O)(=O)[O-])Nc1ccc(NC(=O)c2ccnc([N+](=O)[O-])c2)cc1</smiles>

3<smiles>O=C(Nc1ccc(C(F)(F)F)cc1)c1ccnc([N+](=O)[O-])c1</smiles>

5

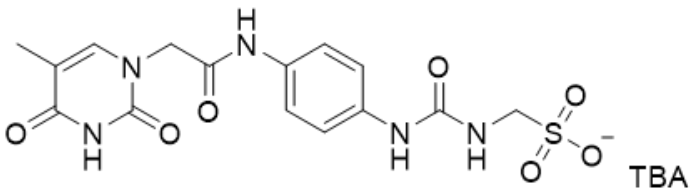

2<smiles>CC(C)COS(=O)([O-])([O-])CNC(=O)Nc1ccc(NC(=O)c2ccnc(N)c2)cc1</smiles>

4

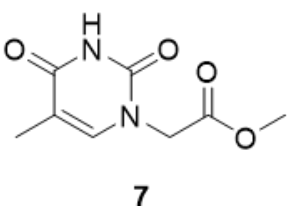

Uncaptioned image 


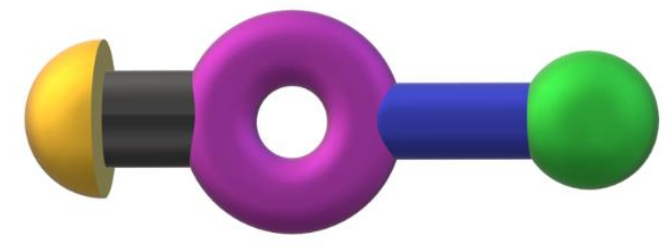

a)

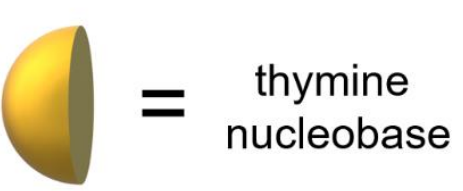

b)

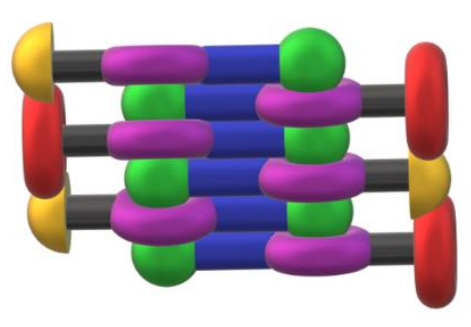

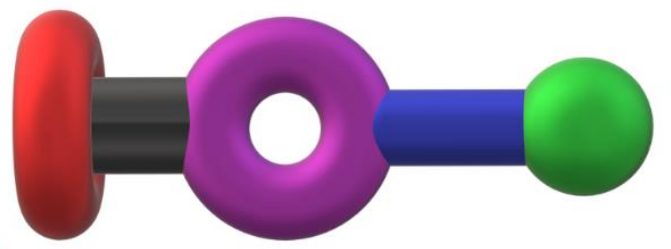

$=$ pseudo adenine nucleobase

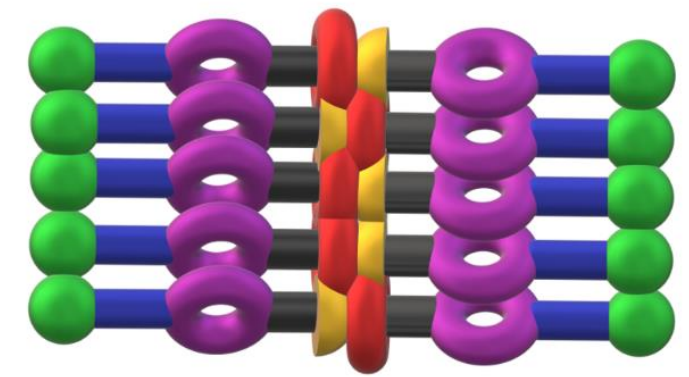

Figure 2. a) Cartoon representing the general structure of a thymine nucleobase (2) and pseudo adenine nucleobase (4) substituted SSA; b) hypothesised, self-associated structures produced by mixtures of $\mathbf{2}$ and $\mathbf{4}$, through either, urea-anion hydrogen bonded complexation or a combination of urea-urea and complimentary nucleobase interactions. 


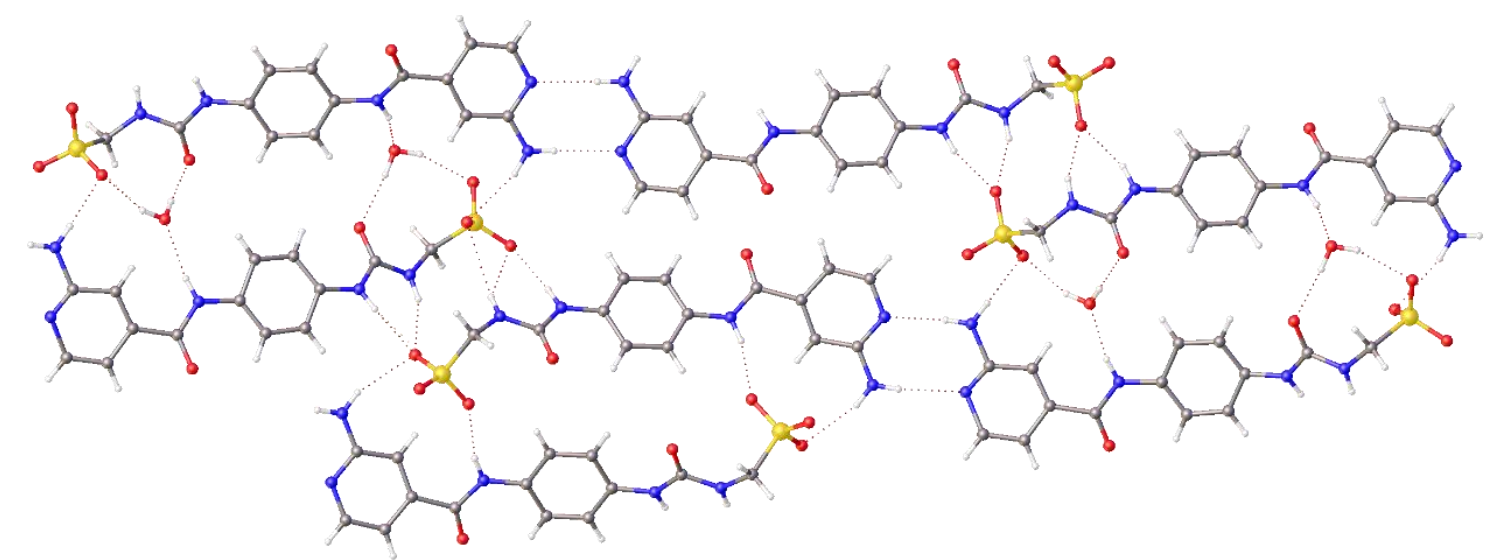

Figure 3. Single crystal X-ray structure of 4, illustrating complex hydrogen bonded selfassociation within the solid state, which includes a combination of urea-anion, amino pyridine-amino pyridine, amine-anion and amide-anion complexation. The tetrabutylammonium (TBA) counter cations and atomic disorder have been omitted for clarity. Grey $=$ carbon, blue $=$ nitrogen, red $=$ oxygen, yellow $=$ sulfur, white $=$ hydrogen, red dashed lines $=$ hydrogen bonds. 


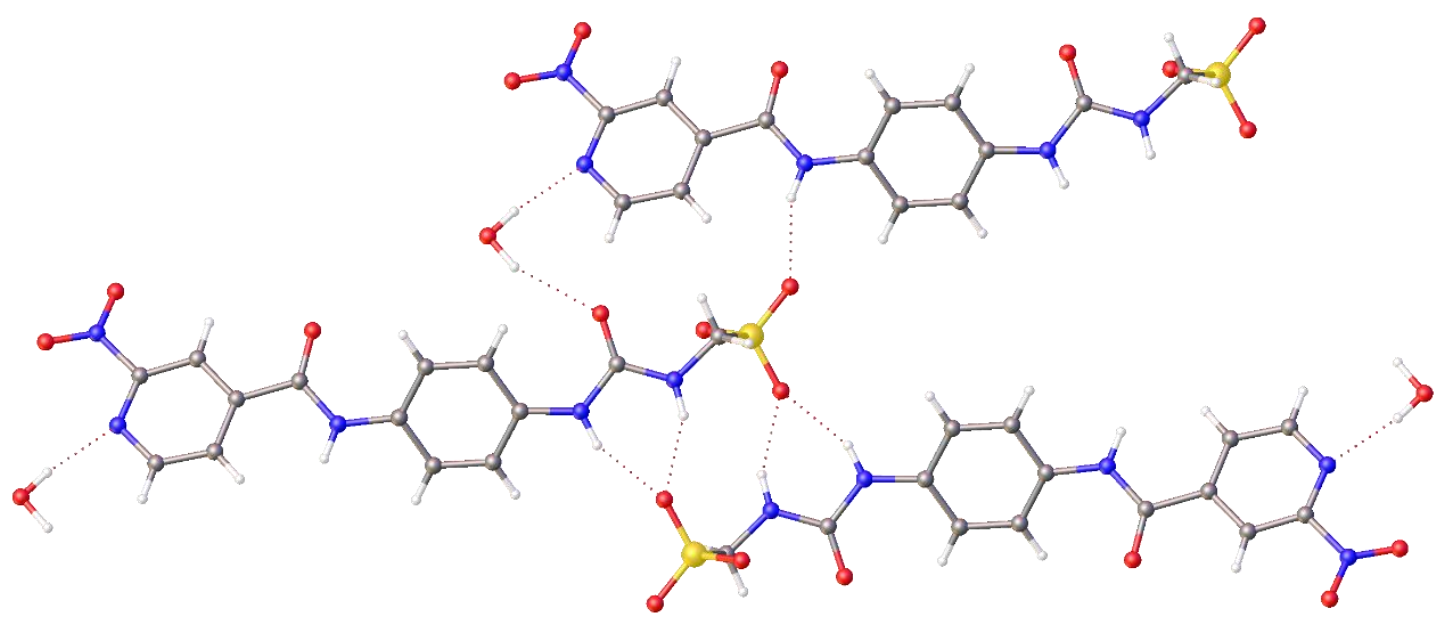

Figure 4. Single crystal X-ray structure of $\mathbf{3}$, illustrating hydrogen bonded selfassociation within the solid state, which includes a combination of urea-anion and amide-anion complexation. The TBA counter cations have been omitted for clarity. Grey $=$ carbon, blue $=$ nitrogen, red $=$ oxygen, yellow $=$ sulfur, white $=$ hydrogen, red dashed lined $=$ hydrogen bonds. 

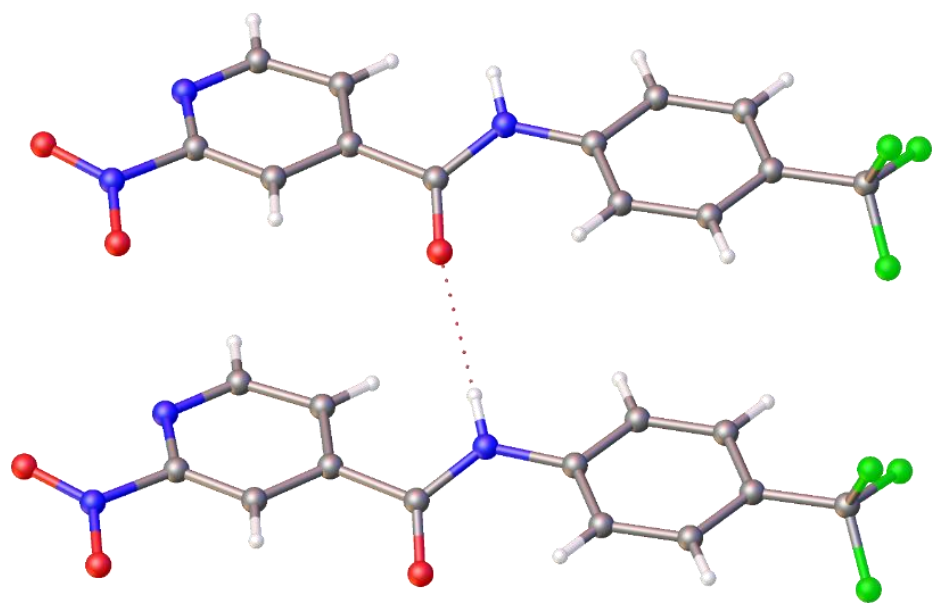

Figure 5. Single crystal X-ray structure of $\mathbf{5}$, illustrating hydrogen bonded tape formation, through amide-amide complexation. Grey $=$ carbon, blue = nitrogen, red = oxygen, green $=$ fluorine, white $=$ hydrogen, red dashed lined $=$ hydrogen bonds . 


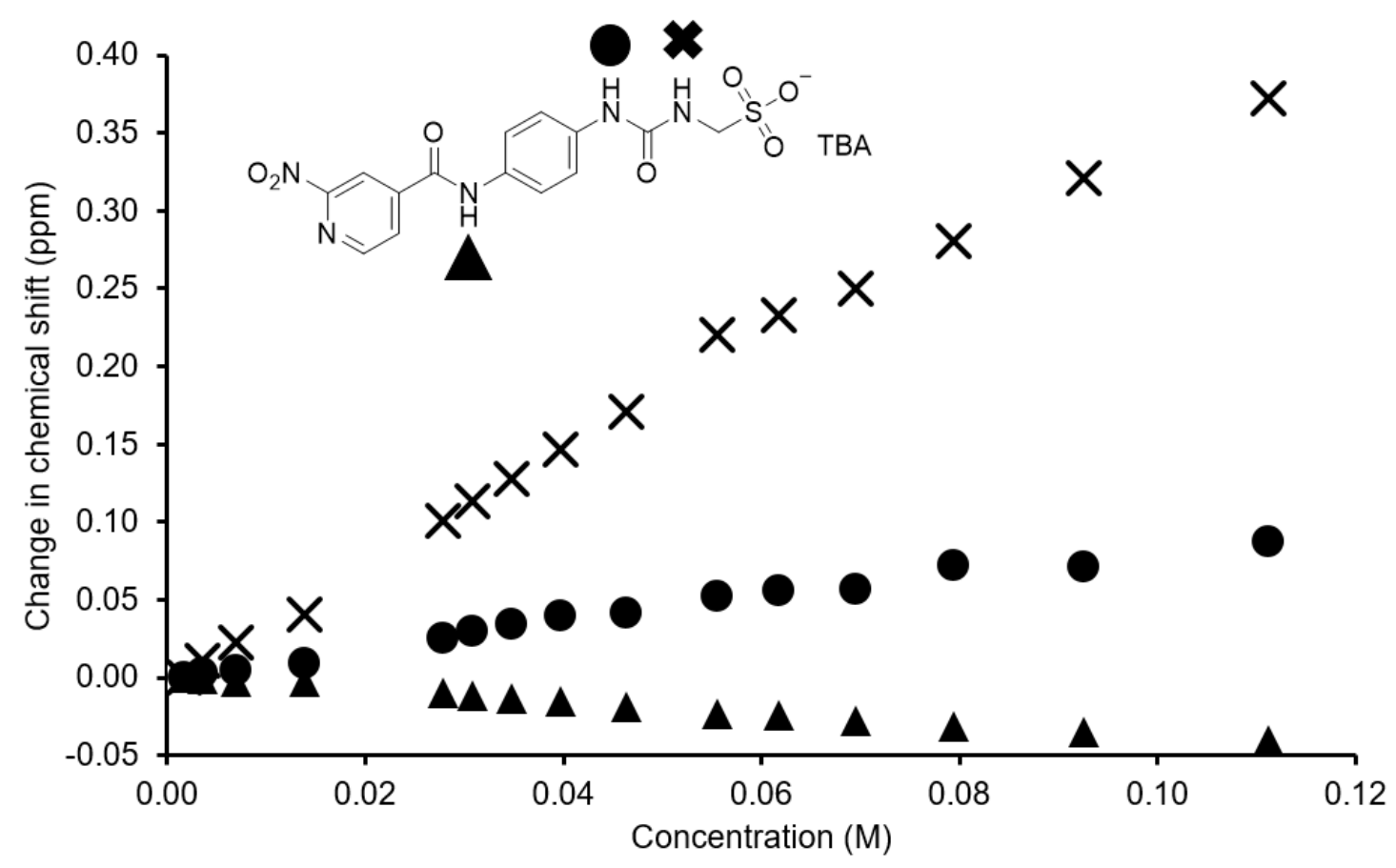

Figure 6. Graph showing the ${ }^{1} \mathrm{H}$ NMR change in chemical shift for the NH resonances with increasing concentration of 3 in DMSO- $d_{6} 0.5 \% \mathrm{H}_{2} \mathrm{O}(298 \mathrm{~K})$. 


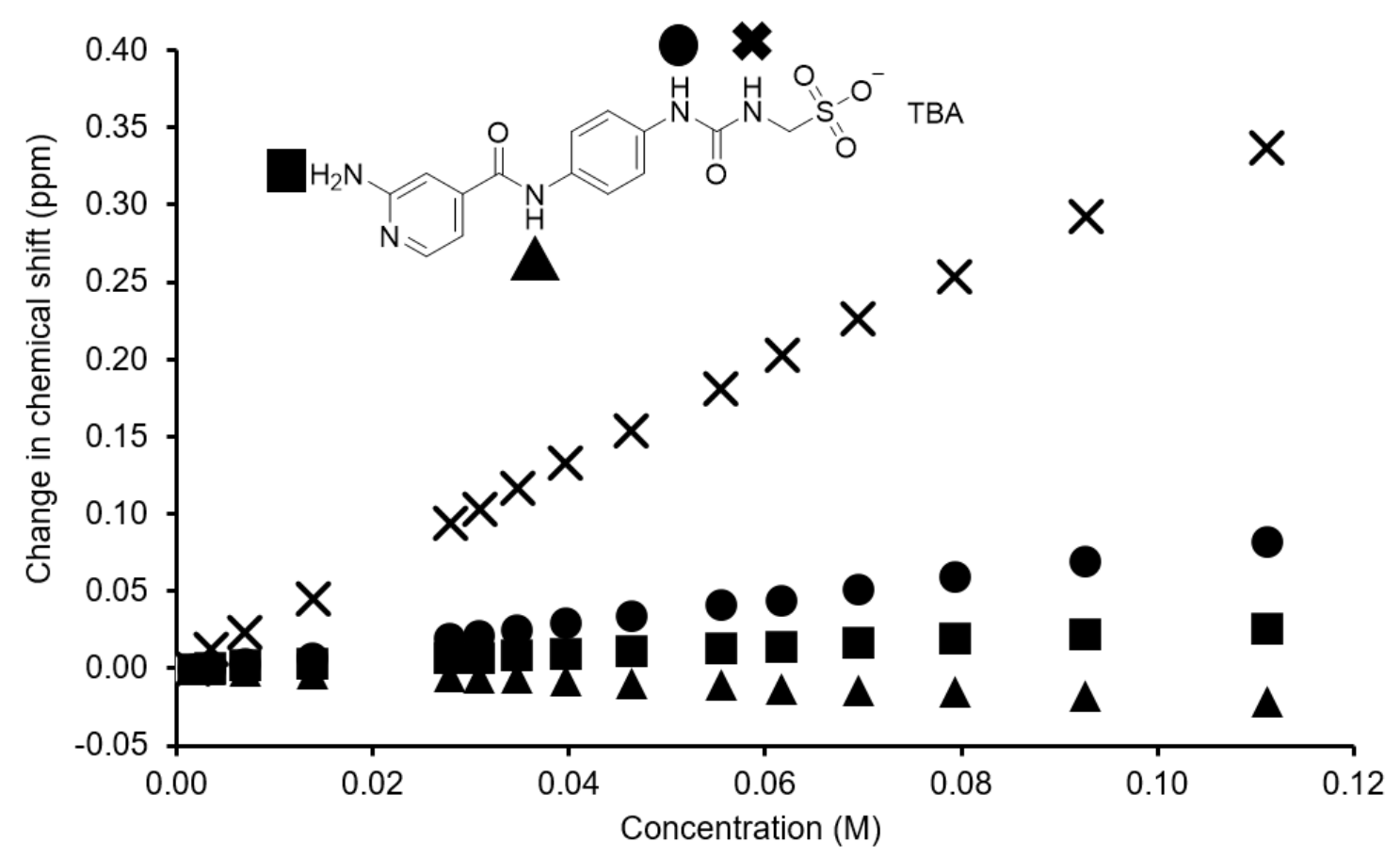

Figure 7. Graph showing the ${ }^{1} \mathrm{H}$ NMR change in chemical shift for $\mathrm{NH}$ resonances with increasing concentration of 4 in DMSO- $d_{6} 0.5 \% \mathrm{H}_{2} \mathrm{O}(298 \mathrm{~K})$. 


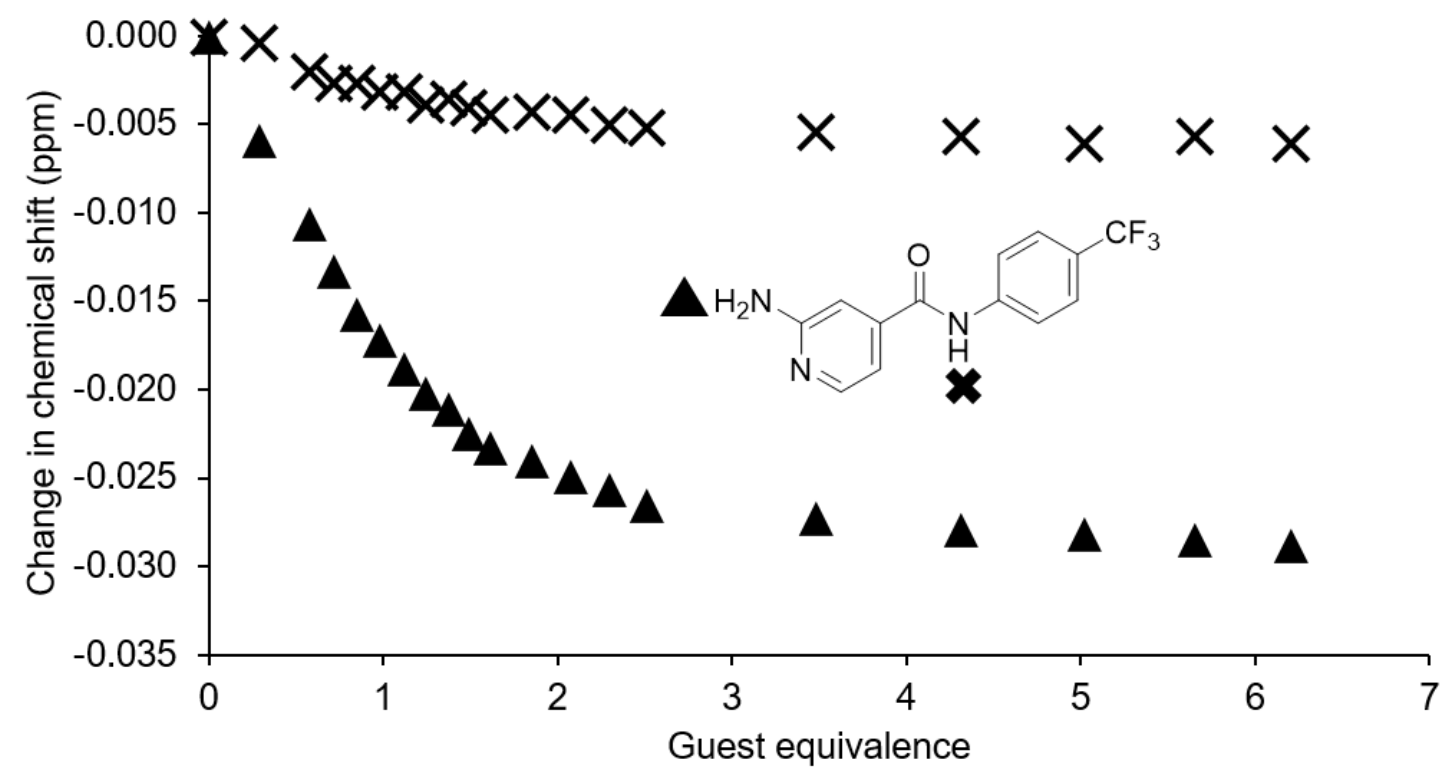

Figure 8. Graph summarising the ${ }^{1} \mathrm{H}$ NMR change in chemical shift for the NHs of 6 (host) with increasing concentration of 7 (guest) in a DMSO- $d_{6} 0.5 \% \mathrm{H}_{2} \mathrm{O}$ solution at $298 \mathrm{~K}$. 


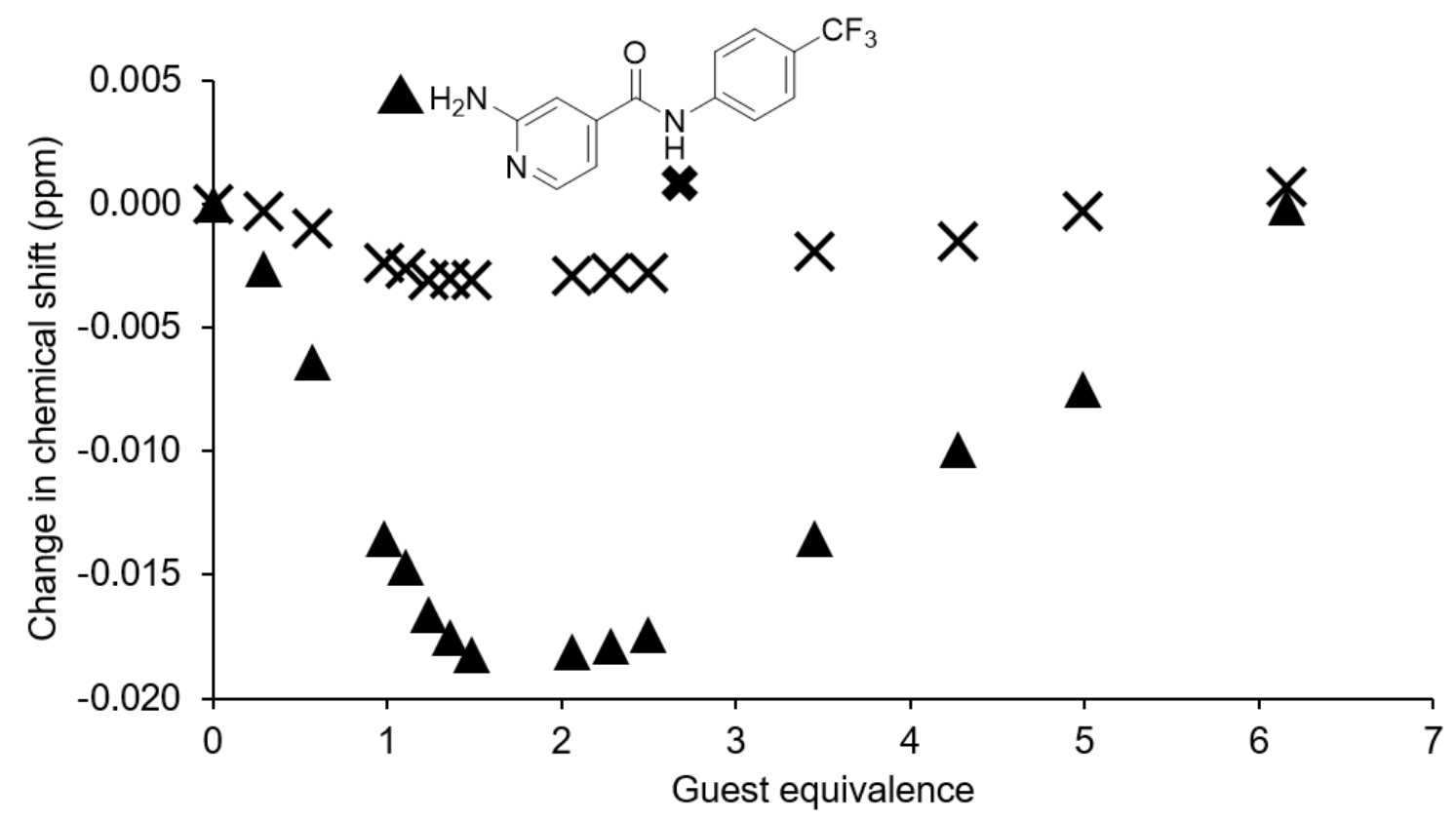

Figure 9. Graph summarising the ${ }^{1} \mathrm{H}$ NMR change in chemical shift for the NHs of 6 (host) with increasing concentration of TBA $\mathrm{HSO}_{4}$ (guest) in a DMSO- $d_{6} 0.5 \% \mathrm{H}_{2} \mathrm{O}$ solution at $298 \mathrm{~K}$. 

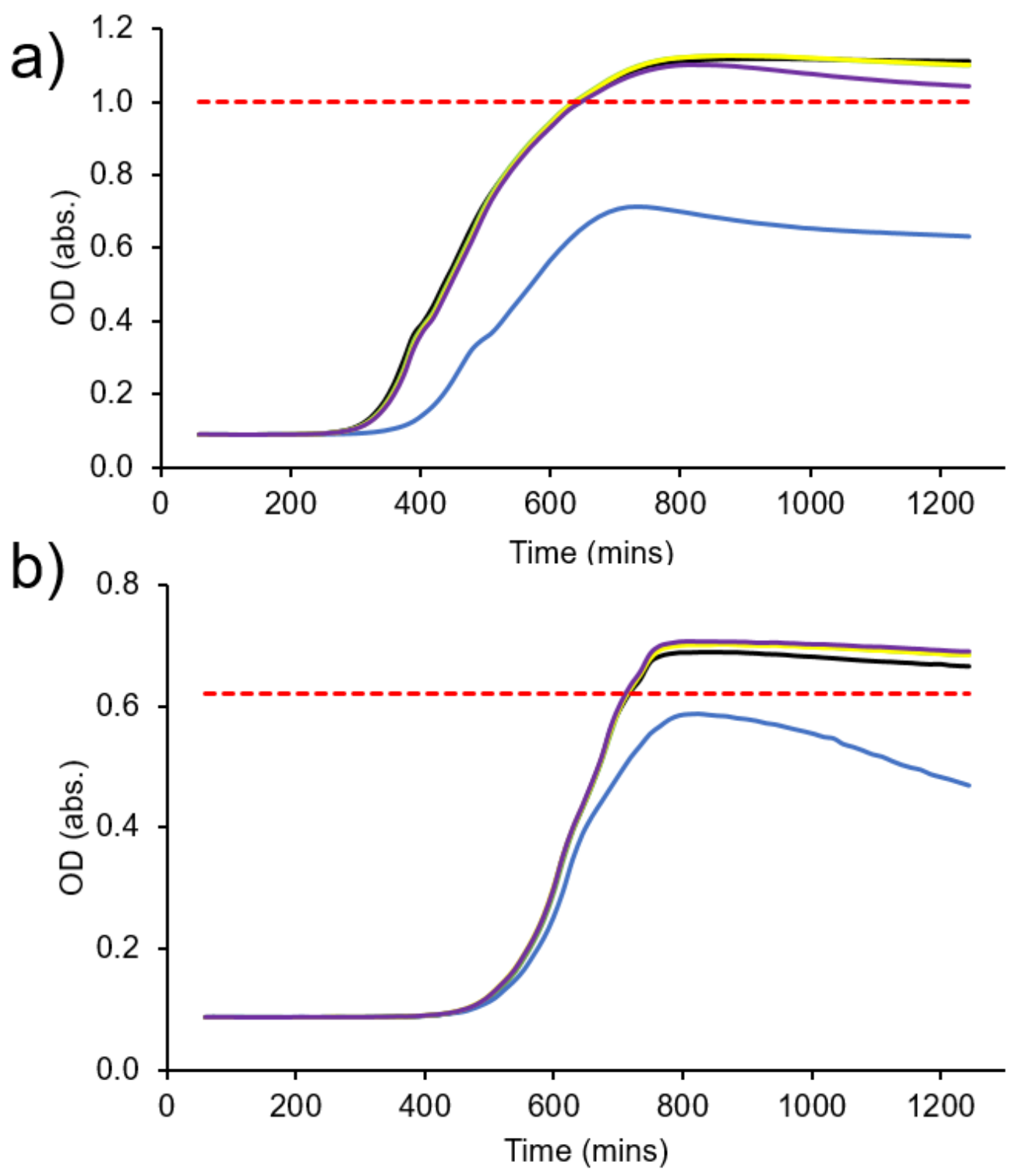

Figure 10. Averaged $(n=3)$ growth curves created from absorbance readings at $600 \mathrm{~nm}$ of a) MRSA USA300 and, b) E. coli DH10B in the presence or absence (black) of compounds $\mathbf{2}$ (green), $\mathbf{3}$ (blue), $\mathbf{4}$ (yellow) and $\mathbf{2 + 4}$ (purple) in a 1:1 mixture at a total molar concentration of $3.3 \mathrm{mM}$, supplied in 1:19 EtOH: $\mathrm{H}_{2} \mathrm{O}$ (black) solution. Red dashed line indicates a $10 \%$ decrease in OD measurement at 900 mins. 